Article

\title{
Energy-Saving UHMW Polymeric Flow Aids: Catalyst and Polymerization Process Development
}

\author{
Muhammad Atiqullah ${ }^{1, *}$, Abdelsalam H. Al-Sarkhi ${ }^{2}{ }^{-}$, Faisal M. Al-Thenayan ${ }^{3}$, \\ Abdullah R. Al-Malki ${ }^{3}$ and Hassan S. Alasiri ${ }^{1}$ (D) \\ 1 Center for Refining \& Petrochemicals, Research Institute, King Fahd University of Petroleum \& Minerals, \\ Dhahran 31261, Saudi Arabia \\ 2 Department of Mechanical Engineering, King Fahd University of Petroleum \& Minerals, Dhahran 31261, \\ Saudi Arabia \\ 3 Saudi Aramco R\&D Center, Dhahran 31311, Saudi Arabia \\ * Correspondence: matiq@kfupm.edu.sa; Tel.: +966-13-860-3898
}

Received: 30 September 2019; Accepted: 25 November 2019; Published: 28 November 2019

check for updates

\begin{abstract}
Crude oil and refinery products are transported worldwide to meet human energy needs. During transportation via pipeline, huge pumping power is required to overcome the frictional pressure drop and the associated drag along the pipeline. The reduction of both is of great interest to industry and academia. Highly expensive ultrahigh molecular weight (UHMW, MW $\geq$ a million Dalton) drag reducing polymers (DRPs) are currently used to address this problem. The present paper, therefore, emphasizes particularly the development of a high-performance catalyst system that synthesizes DRPs (using higher alpha-olefins) - a highly promising cost reduction alternative. This homogeneous catalyst system features a new concept that uses a cost-effective titanium-based Ziegler-Natta precatalyst and a cocatalyst•Lewis base complex having both steric hindrance (around $\mathrm{N}$ heteroatom) and electronic effect. This novel work, which involves precatalyst-cocatalyst molecular separation and cocatalyst monophenyl amine association-dissociation phenomena, already generated several US patents. The subject catalyst prepares UHMW DRPs at room temperature, avoiding the use of zero and sub-zero temperatures. The resulting product almost tripled the rate of transportation of a selected grade of refinery product and saved about $50 \%$ pumping energy at ppm level pipeline concentration. It is also very easily soluble. Hence, massive modification of existing pipeline will be unnecessary. This will save additional infrastructure cost. This paper also summarizes challenges facing the development of improved heterogeneous catalysts, dispersed polymerization process, molecular simulation-based DRP product formulation, and model/theory of turbulent mixing and dispersion in the transportation pipeline setting.
\end{abstract}

Keywords: drag reducing polymer; crude oil; refinery product; Ziegler-Natta precatalyst; 1-hexene-dodecone copolymerization; dispersed polymerization process; product formulation; molecular simulation; turbulent mixing and dispersion

\section{Introduction}

Crude oil and refinery products are transported using pipelines. Figure 1 shows the very high production level of global 2018 crude oil and refined product productions [1,2]. During transportation, the pressure drastically drops due to interfacial friction between the pipe wall and the flowing fluid. Consequently, the desired throughput cannot be maintained. Increasing the input pressure and introducing higher flow rates seem to be quick and facile solutions. However, design limitations on pipelines limit the level of pressure that can be applied. The pressure further drops when fluids are transported over long distances. Consequently, the equipment and operational costs increase. Therefore, 
the efficient transport of crude oils and refinery products is a great challenge [3-7]. To overcome this challenge, highly expensive ultrahigh molecular weight (UHMW, MW $\geq$ a million Dalton) drag reducing polymers (DRPs), which are commercially available, are commonly used.
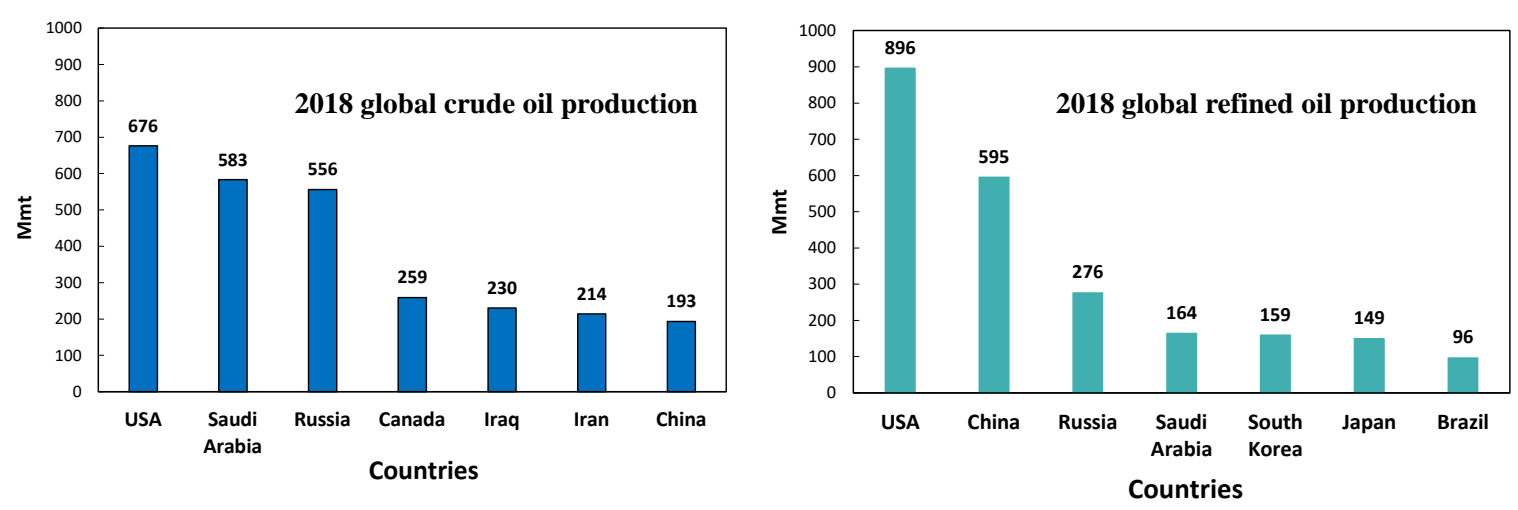

Figure 1. Global crude oil and refined product production capacities [1,2].

The DRP literature can be mainly divided into journal publications and patents. The first publication originated from Toms in 1949 [8]. He reported in the First International Rheology Congress that long-chain polymethyl methacrylate (PMMA) reduced the single-phase turbulent wall friction by $80 \%$. This increased the fluid flow rate at constant pressure gradient. Since that time to the present, DRP-mediated fluid flow remains a very active research area. Consequently, DRPs are currently used to transport fluid in very long-distance intra- and trans-country pipe lines [9-14]. The subsequent journal publications mostly report about the hydrodynamic theories of drag reduction (DR) and the effects of DRP MW and stability, rheology, multiphase flow, hydrodynamic variables, conduit configuration, surfactant-based product formulation, etc. on the performance of commercial DRPs [14-23]. These references and the citations therein can be pursued for the details.

Commercial DRPs are made catalytically, mostly by polymerizing linear alpha-olefins. Therefore, we review catalyst development research in this area as follows. The DRP catalyst research is mostly covered by patents. The central concept comprises using the second generation $\alpha-\mathrm{TiCl}_{3} \mathrm{Ziegler-Natta}$ $(\mathrm{Z}-\mathrm{N})$ precatalyst with an organoaluminum cocatalyst $[24,25]$. Note that $\beta-\mathrm{TiC}_{3}$ only polymerizes diolefins but not mono-olefins, such as linear alpha-olefins [26]. Figure 2 shows the crystal structures of both forms of $\mathrm{TiC}_{3}$.
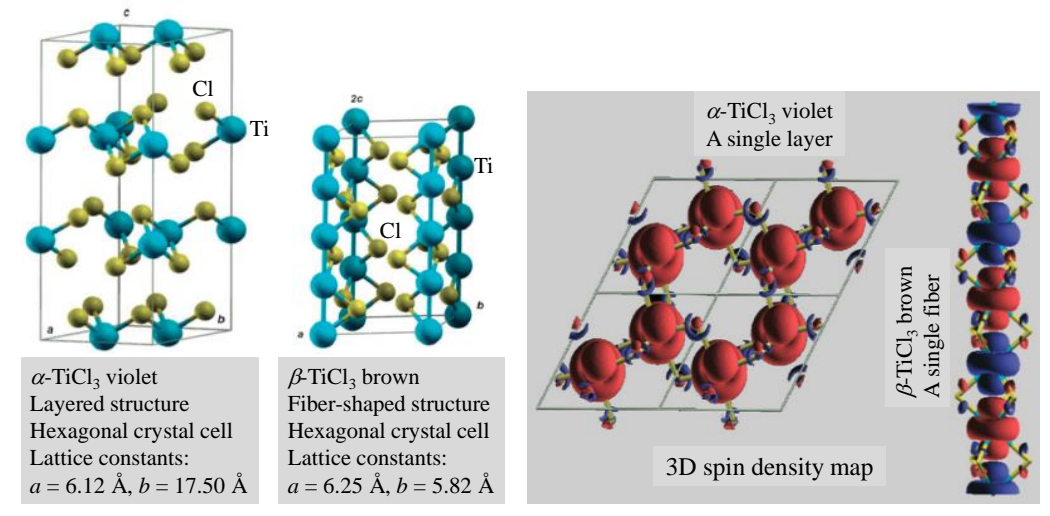

Figure 2. Structure of solid $\mathrm{TiCl}_{3}$ [27].

All the patents modified the above basic catalyst system by introducing a Lewis base (LB) electron donor to block the active centers that catalyze the formation of undesirable low molecular weight poly(alpha-olefin) backbones. The referenced LBs can be divided into Type I LBs and Type II LBs. Type 
I LBs are non-phosphorous and Type II LBs are phosphorous. Type I includes ether [28], ketone [29,30], pyridine and piperidine [31], etc. Type II lists phosphine, phosphite, etc. [32]. Additionally, a third family of patents uses aluminoxanes alone, or combined with $\mathrm{Z}-\mathrm{N}$ alkyl aluminum cocatalysts [33-37]. All these patents showed variation in components and composition. The resulting poly(alpha-olefin)s were mostly characterized by measuring the standard solution viscosity, which was used to confirm the formation of UHMW product. The cited patents show the following:

- Low catalyst activity;

- Requirements of $0^{\circ} \mathrm{C}$ and below, and very long polymerization time ( $\geq 12 \mathrm{~h}$ ) to synthesize the DRP;

- Low drag reduction ( 13.4\%); and

- Use of hazardous catalyst adjuvant(s), and costly gel-prone aluminoxane cocatalysts.

The patents also did not report any catalyst characterization work, fundamentals, or insight. Therefore, enough room to develop high-performance catalyst and DRP polymerization process exists. Note that a high activity catalyst is a pre-requisite to develop cost-effective commercial DRP process because it increases yield and production volume. This is why the present study particularly addresses how to enhance DRP catalyst activity.

\section{Results and Discussion}

\subsection{Present Patented Catalyst Design Concept and Composition}

The catalytic synthesis of UHMW DRP has two requirements. One is kinetic and the other is thermodynamic. The kinetic requirement demands that the rate of chain propagation $R_{p}$ should be, on principle, exceedingly large. On the contrary, the rate of chain termination $R_{t}$ (originating from various active chain transfer reactions) should ideally approach zero. The thermodynamic requirement, in terms of activation energy, is just the opposite. See Figure 3. An embedded challenge in this context is the following. In organometallic-catalyzed olefin polymerization, the catalyst activity and the resulting MW are inversely related. How to strike a balance between both poses a challenge. Our patented catalyst design concept attempts meeting the above requirements and overcoming this challenge [23-25].

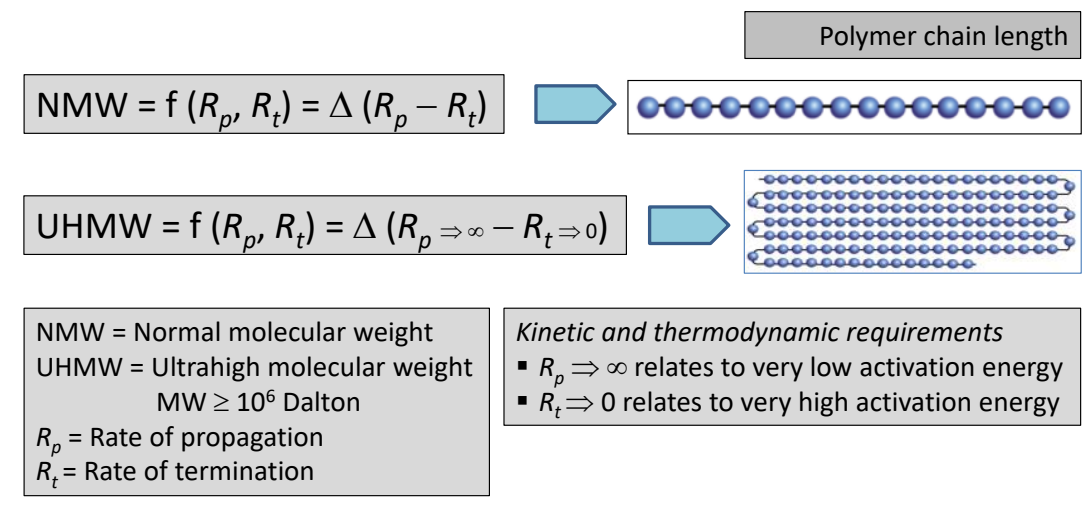

Figure 3. Kinetic and thermodynamic requirements for producing ultrahigh molecular weight drag reducing polymer (UHMW DRP).

The above catalyst design concept is summarized here. To meet Figure 3 kinetic and thermodynamic requirements, we proposed to use (nucleophilic) Lewis base electron donors that featured the following [38-40]:

- They simultaneously show steric hindrance and electronic effect. Steric hindrance is achieved by the bulky substituents around the heteroatom, which reduces the access of the related base functionality to the Lewis acid alkyl aluminum cocatalyst. 
- Electronic effect is obtained by placing electron-withdrawing substituents on the heteroatom to reduce its electron density. Consequently, the (electrophilic) Lewis acid alkyl aluminum cocatalyst $\bullet$ Lewis base complex presumably dissociates (in a nonpolar medium) under the DRP synthesis condition, and consequently the catalyst productivity increases. The introduction of this dissociation phenomenon and the control of precatalyst-cocatalyst molecular separation are the key to the subject novel catalyst design. Aromatic substituents are especially useful because they are relatively inert toward other catalyst components.

Our patents illustrate the above overall catalyst constitutive coordination/complexation and precatalyst-cocatalyst molecular separation concept and structure, first by forming an alkylaluminum cocatalyst Lewis base (LB) complex, and next by contacting this complex with the transition metal precatalyst to make the final catalyst [23-25]. A preferred example of the above LB is a tertiary monophenyl amine, belonging to the group comprising $\mathrm{N}, \mathrm{N}$-diethylaniline, N-ethyl-N-methylparatolylamine, N,N-dipropylaniline, N,N-diethylmethylamine, and combinations thereof.

\subsection{Catalyst and Polymer Science Underlying the Present Patented Catalyst System}

Figure 4 shows the reference versus our patented catalyst structure, and compares the productivity of a given example of the former with that of the latter. The patented catalyst formulation PatCat, prepared as per the novel concept reported in Section 2.1, shows to be 1.4 times more productive than the reference catalyst RefCat. This can be explained based on the following postulations. First, the steric hindrance, due to N,N-diethylaniline, widens the precatalyst-cocatalyst molecular separation. The larger is this separation, the lower is the energy barrier associated with each copolymerization insertion and propagation step. This situation is analogous to ion-pair separation that (i) concerns metallocenium cation and methylaluminoxane or borate anion, and (ii) applies to olefin polymerization [41,42]. Second, the electron-withdrawing phenyl group decreases the electron density on $\mathrm{N}$, which makes (diethyl aluminum chloride) DEALC $\bullet \mathrm{N}, \mathrm{N}$-diethylaniline complex prone to dissociate. Resultantly, access of monomer (preferably, 1-hexene because of the smaller size) to the vacant coordination site, its insertion into the growing copolymer chains, and chain growth-all concertedly increase. See Scheme 1. Therefore, PatCat showed higher productivity than RefCat, and the resulting copolymer chain length also enhanced. Note that increased catalyst productivity increases production volume, which consequently reduces production cost. Therefore, our patented catalyst adds value to DRP process development and economics.

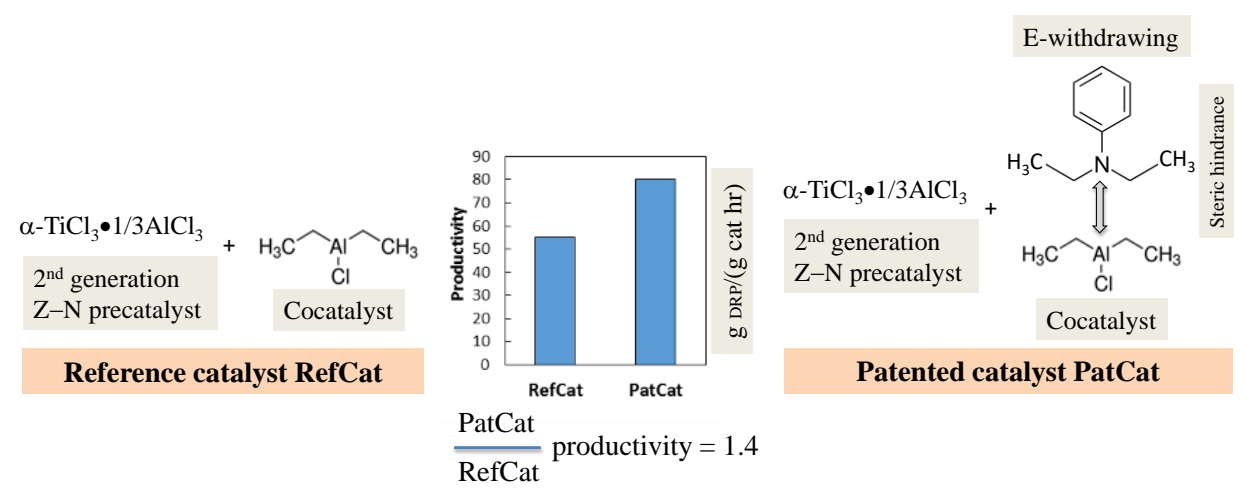

Figure 4. Productivity of the reference and patented catalysts. 


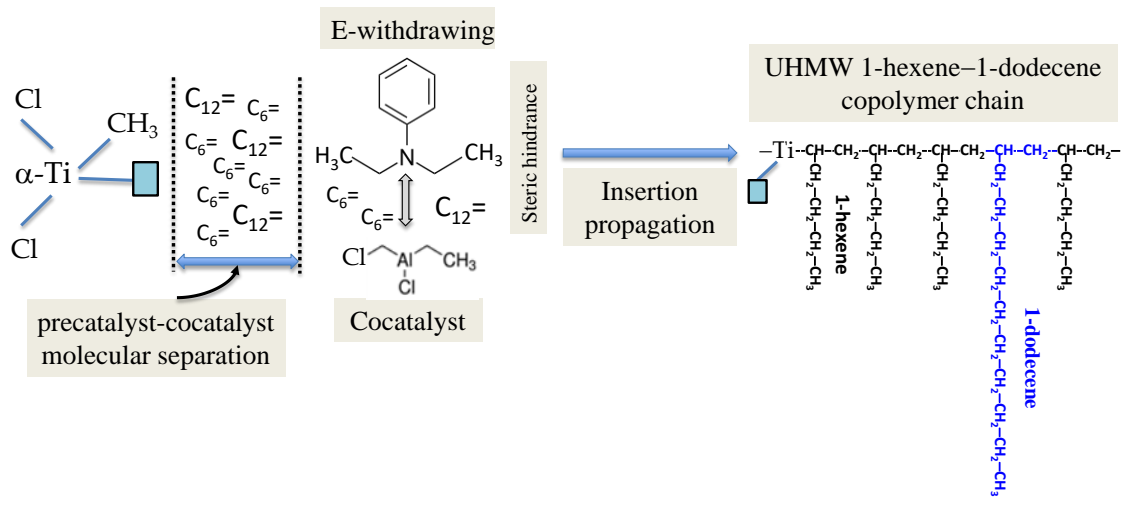

Scheme 1. Insertion, propagation, and chain growth in 1-hexene-1-dodecene copolymerization mediated by PatCat.

Figure 5 shows the effects of cocatalyst formulation type, and DRP MW and microstructure (from a qualitative perspective) on DR\%. By DRP microstructure, we mean monomer/comonomer sequence and side chain distribution in the copolymer backbone. The following important findings are summarized below.
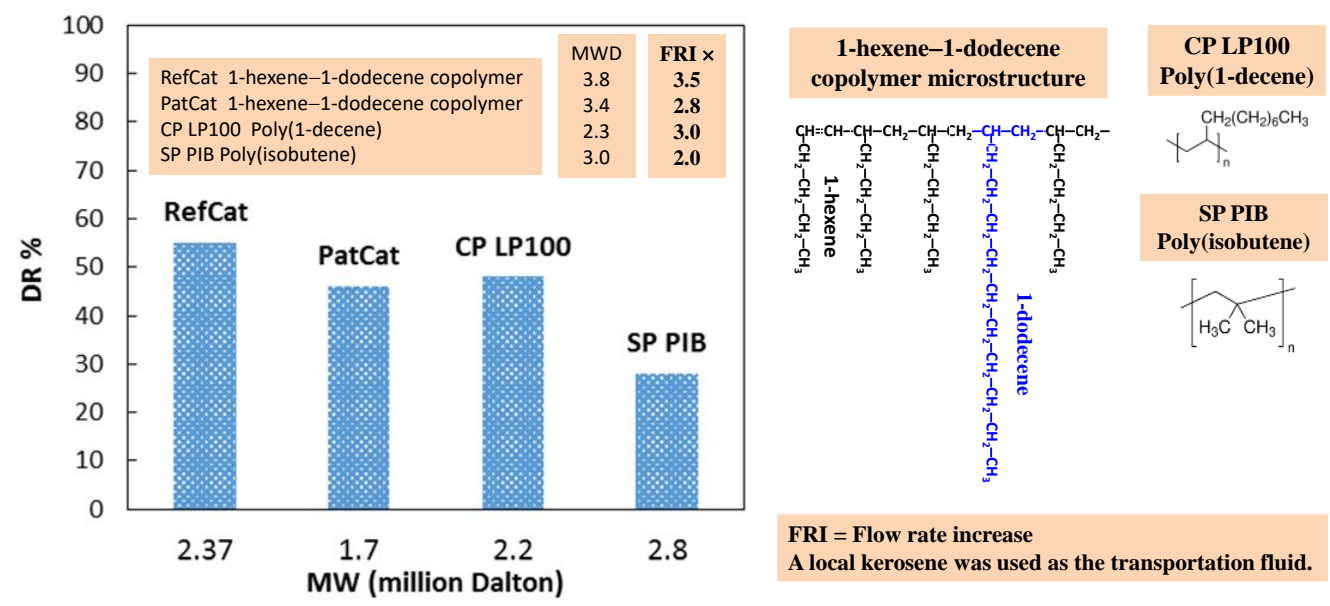

Figure 5. Effect of cocatalyst formulation type, MW, and DRP microstructure on drag reduction (DR)\%.

First, compare the DR\% of PatCat DRP with that of RefCat DRP. The former approaches that of the latter even for a much lower UHMW value. The MW of PatCat DRP is 1.70 million Dalton while that of RefCat DRP is 2.37 million Dalton. Scheme 2 illustrates the related major $\beta$-hydride chain transfer reaction that terminates the 1-hexene-1-dodecene copolymer chain length. The overall electronic environment and the steric hindrance around Ti affect the suppression of the above chain transfer reaction. This means that the patented catalyst is capable of regulating the microstructure of the 1-hexene-1-dodecene copolymer in such a manner that commensurate DR\% can also be achieved using lower UHMW value DRP. Increased UHMW value DRP has been reported as a pre-requisite to improving DR\% $[5,8,9,12,13,15]$. This work does not favor this argument. To the best of our knowledge, such a finding has not been reported in the literature. 


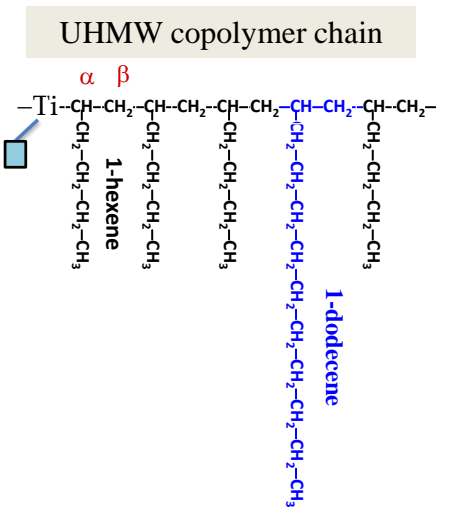

UHMW 1-hexene-1-dodecene copolymer $\alpha \beta$
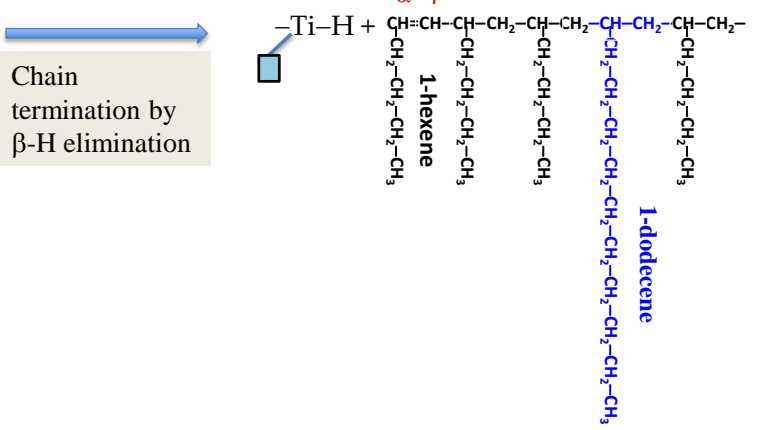

Scheme 2. Major chain termination reaction in 1-hexene-1-dodecene copolymerization mediated by PatCat and RefCat.

The above finding has significant scientific value. This will motivate the concerned researchers to revisit the current mechanism of turbulent drag reduction and DRP rheology, which will set new directions to fundamental and applied research in this important subject. The $45 \%$ DR of the PatCat DRP signifies the following. The resulting product almost triples the rate of transportation of a selected grade of refinery product and saves about $50 \%$ pumping energy at ppm level pipeline concentration. The flow rate increase (FRI) was calculated using the following relation [26]:

$$
F R I=\frac{1}{1-\left(\frac{\% D R}{100}\right)^{0.55}} \times 100 .
$$

Additionally, the use of increased UHMW DRPs has the following practical disadvantages. They dissolve less readily in hydrocarbon fluid than the lower UHMW value DRPs. The solution viscosity also increases with MW. Therefore, the injection procedure becomes cumbersome and more energy consuming. Therefore, we show how these disadvantages can be overcome through designing the catalyst in an appropriately novel fashion.

Second, evaluate the DR\% performance of PatCat DRP against that of CP LP100 and SP PIB. CP LP100 is a poly(1-decene)-based commercial DRP formulation whereas SP PIB is an UHMW poly(isobutene) from Scientific Polymer Products Inc. Both products are homopolymers. This evaluation establishes that the as-synthesized PatCat DRP, despite having lower UHMW, shows comparable to higher DR\% without making a DRP formulation. This is another manifest of the merits of our patented catalyst and the UHMW 1-hexene-1-dodecene DRP it synthesized. This improved PatCat DRP performance may be attributed to the important role that particularly the longer and bulkier $n$-decyl branch of the above 1-hexene-1-dodecene copolymer plays, under such a situation, in the following areas $[5,8,9,12,13,15]$ :

- Stretching the copolymer chain with respect to equilibrium conformations;

- Increasing solution extensional viscosity;

- Dampening turbulent eddies; and

- Thickening of the viscous laminar sublayer.

The present catalyst-mediated copolymerization route is apt to shift the DRP synthesis process from $0{ }^{\circ} \mathrm{C}$ and below to room temperature and above.

\section{Materials and Methods}

All the procedures, related to catalyst formulation, DRP synthesis, and drag reducing (DR) performance evaluation, are detailed in our patents [38-40]. Therefore, they were only summarized here (as appropriate). A local kerosene was used as the transportation fluid. 
The DRPs in this work refer to 1-hexene-1-dodecene copolymers. Jubail United Petrochemical Company Almuttahida (Al-Jubail, Saudi Arabia) —a SABIC affiliate—donated 1-hexene and 1-dodecene. The $\alpha-\mathrm{TiCl}_{3} \bullet 1 / 3 \mathrm{AlCl}_{3} \mathrm{Z}-\mathrm{N}$ precatalyst was purchased from MCat Germany whereas diethyl aluminum chloride (DEALC) cocatalyst, triisobutyl aluminum (TIBA), toluene, 1,2,4 trichlorobenzene (TCB), and N,N-diethylaniline were procured from Merck (earlier Sigma-Aldrich). CP LP100 is a poly(1-decene)-based commercial DRP formulation whereas SP PIB-UHMW poly(isobutene)—was procured from Scientific Polymer Products Inc (Ontario, NY, USA).

Toluene was demoisturized by contacting it overnight with $4 \mathrm{~A}$ molecular sieve, activated at $230^{\circ} \mathrm{C}$. The toluene Schlenk flask (containing the molecular sieve) was shaken from time to time, evacuated, and purged with argon until the moisture level dropped to $\leq 10 \mathrm{ppm}$.

These DRPs were synthesized using a computer-aided AP Miniplant polymerization reactor equipped with a $1 \mathrm{~L}$ Büchi glass reactor (Flawil, Switzerland). First, the reactor was thoroughly cleaned and baked at $120^{\circ} \mathrm{C}$ for $2 \mathrm{~h}$; then, it was cooled to room temperature. The required amount of toluene was added to the reactor by a syringe. Of $1.0 \mathrm{M}$ triisobutyl aluminum (TIBA) $1.0 \mathrm{~mL}$ was added to toluene as the scavenger. The precatalyst solution and the cocatalyst formulation were prepared in dried toluene inside a highly inert glove box. All additions and manipulations were done under inert argon environment inside the reactor. In the RefCat [9,10], the DEALC: $\left(\mathrm{TiCl}_{3} \bullet 1 / 3 \mathrm{AlCl}_{3}\right) \cong 2-4$ while in the PatCat, an equimolar N,N-diethylaniline was premixed with DEALC. The copolymerization of 1-hexene with 1-dodecene was conducted at equimolar ratio at $20^{\circ} \mathrm{C}$ for $5 \mathrm{~h}$. The reaction was quenched using acidic methanol. The copolymer concentration in the reaction mixture was determined by drying a given volume of it at $40^{\circ} \mathrm{C}$ in a vacuum oven.

A Polymer Laboratory gel permeation chromatography (GPC) instrument (Salop, UK) measured the average molecular weight of the as-synthesized DRPs. The column temperature was set at $135^{\circ} \mathrm{C}$. The DRP sample (about $1.0 \mathrm{mg}$ ), taken in a $1 \mathrm{~mL}$ vial, was dissolved in $1.0 \mathrm{~mL}$ butylated hydroxy toluene BHT-stabilized 1,2,4 trichlorobenzene (TCB) as follows. The vial was shaken first in a regular hot-plate shaker, then in the warming compartment of the GPC instrument-both at $135^{\circ} \mathrm{C}$-for about $5 \mathrm{~h}$ to completely dissolve the sample.

Before injecting a sample, the differential refractive index (DRI) detector was purged for $4 \mathrm{~h}$ using TCB (1 mL/min) to obtain stable baseline. The inlet pressure (IP) and the differential pressure (DP) outputs were also purged for $1 \mathrm{~h}$. The above flow rate of TCB was used, and each sample was analyzed for $35 \mathrm{~min}$.

The instrument was calibrated using nine polystyrene standards whose peak molecular weights ranged from 1530 to 15 million Dalton. The MWs of the as-synthesized DRPs were determined using this calibration curve, the corresponding chromatograms, and Polymer Laboratory GPC software.

The glass transition temperatures $\left(T_{g} s\right)$ of the above DRPs, because of some limitation in our DSC (differential scanning calorimeter) instrument (Pittsburgh, PA, USA), were calculated as follows. The preferred experimental $T_{g} \mathrm{~s}$ of poly(1-hexene) $-54{ }^{\circ} \mathrm{C}[43,44]$, and poly(1-dodecene) $-25{ }^{\circ} \mathrm{C}[43,45]$ were consolidated from the related literature. Poly(1-dodecene) has the longer and bulkier $n$-decyl branch (which makes rotation difficult), whereas the poly(1-hexene) $n$-butyl branch features the opposite. Hence, poly(1-dodecene) has higher $T_{g}$ than poly(1-hexene). The $T_{g}$ of the 1-hexene-1-dodecene copolymer $T_{g}$ copolymer, as a function of the average 1-dodecene mole fraction $m_{2}$, was estimated applying the following equations [46,47] that use $T_{g} \mathrm{~s}$ of poly(1-hexene) and poly(1-dodecene). Figure 6 plots this relation.

$$
\begin{gathered}
T_{g \text { copolymer }}=\frac{\left(1-w_{2}\right) T_{g 1}+k w_{2} T_{g 2}}{\left(1-w_{2}\right)+k w_{2}}, \\
T_{g \text { copolymer }}=\left(1-w_{2}\right) T_{g 1}+w_{2} T_{g 2} k=1, \\
\frac{1}{T_{g \text { copolymer }}}=\frac{\left(1-w_{2}\right)}{T_{g 1}}+\frac{w_{2}}{T_{g 2}} k=\frac{T_{g 1}(K)}{T_{g 2}(K)},
\end{gathered}
$$




$$
w_{2}=\frac{1}{M W_{1}} \frac{1}{\left(\frac{1}{M W_{1}}+\frac{1}{m_{2} M W_{2}}-\frac{1}{M W_{2}}\right)},
$$

where $T_{g 1}$ and $T_{g 2}$ are the glass transition temperatures of poly(1-hexene) and poly(1-dodecene), respectively. $M W_{1}$ is the molecular weight of 1-hexene (84.16 Dalton) whereas $M W_{2}$ is that of 1-dodecene (170.33 Dalton).

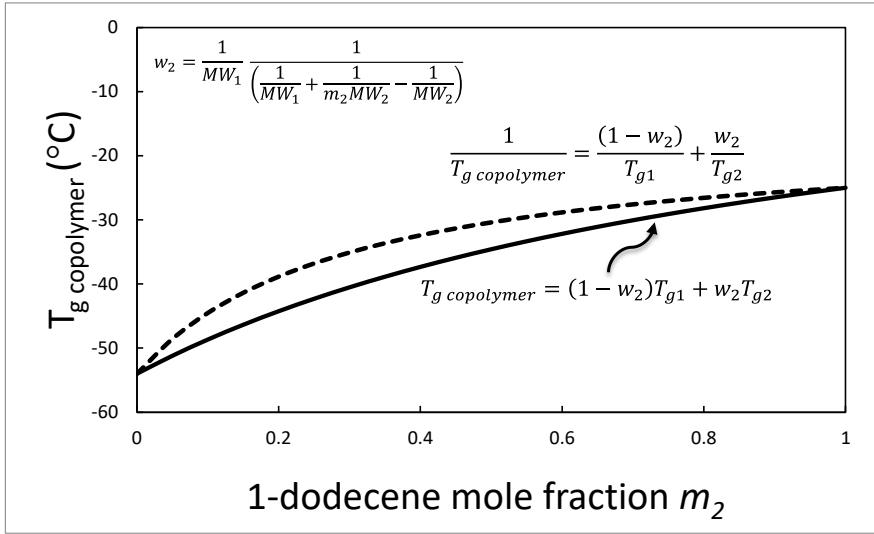

Figure 6. Estimated glass transition temperatures of 1-hexene-1-dodecene copolymers as a function of its average 1-dodecene mole fraction.

The molecular size of 1-dodecene is twice that of 1-hexene. Therefore, the insertion of 1-dodecene in the growing copolymer chain will be restricted due to diffusion limitation. A maximum of 5 mole\% average 1-dodecene incorporation will be a reasonable assumption. Hence, the $T_{g}$ of the as-synthesized 1-hexene-1-dodecene copolymers are expected to be limited as $-52.00{ }^{\circ} \mathrm{C} \leq T_{g} \leq-48.60{ }^{\circ} \mathrm{C}$.

The DRP test facility, a simplified version of which is shown in Figure 7, was self-designed and fabricated by AP Miniplant Germany (AP Miniplant GmbH, Lindewerra, Germany). It physically consists of a $200 \mathrm{~L}$ experimental fluid tank and an oil rotary pump with axial face sealing. The flow loop, made of a 0.4 inch inner diameter SS pipe, is $5.0 \mathrm{~m}$ long. The horizontal section includes two Siemens SITRANS P DSIII HART pressure transmitters (Munich, Germany). These pressure transmitters, situated at $1.5 \mathrm{~m}$ and $1.0 \mathrm{~m}$ length along the flow pipe, measure the pressure difference.

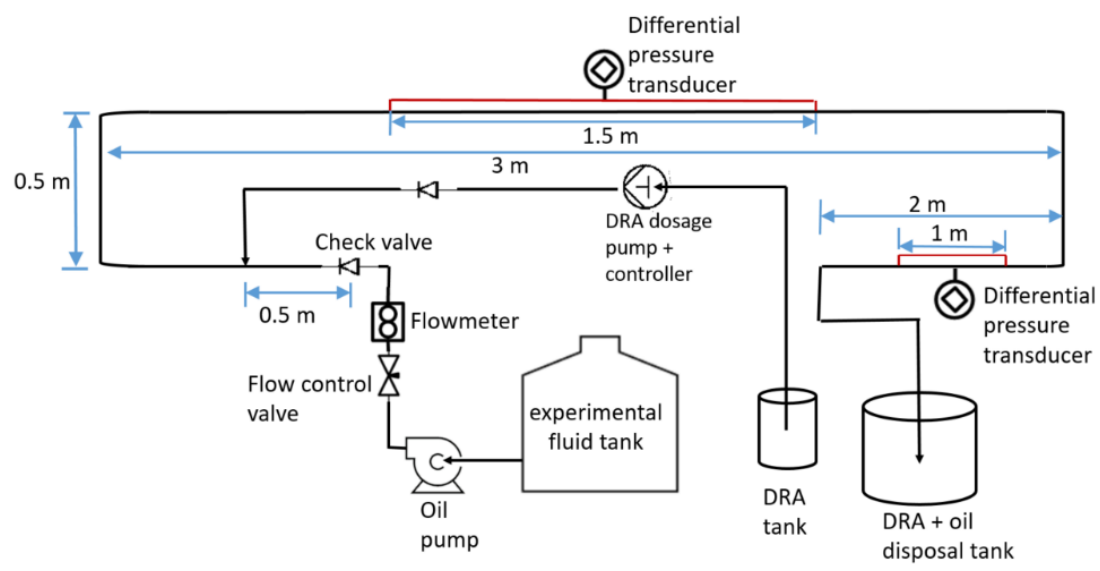

Figure 7. DRP test facility used for performance evaluation.

The DR performance of the experimental $\alpha$-olefin copolymers was evaluated, using the above test facility, as follows. A diaphragm pump injected the concentrated DRP master solution into the pipeline transportation liquid (a local kerosene). The DRP was carefully introduced after the oil pump to avoid polymer degradation (by the rotating pump impeller) and achieved good mixing before entering the 
pressure measurement section. A Vortex Flowmeter (DN15 Sandwich) measured the volumetric flow rate of the kerosene up to $85 \mathrm{~L} / \mathrm{min}$. A check valve, placed after the flow meter, prevented the liquid back flow. On the other hand, a needle flow control valve, installed before the flowmeter, adjusted the flowrate. A built-in data acquisition system recorded the pressure drops (at $1.5 \mathrm{~m}$ and $1.0 \mathrm{~m}$ length along the flow pipe), temperature, and the corresponding volumetric flowrate.

Before DRP performance evaluation, the test loop was calibrated to evaluate system reliability, using a selected grade of kerosene. Figure 8 shows the related calibration curve that plots the pressure drop per unit length $(\Delta \mathrm{P} / \mathrm{L})$ as a function of the Reynolds number $(R e)$. It has two parts-linear laminar region for $R e<2000$ and the nonlinear turbulent region for $R e>3000$. The linear laminar flow behavior confirms the accuracy of the pressure transducer at very low flowrate. However, it does not apply to evaluate the performance of DRP, which reduces the frictional drag only in the turbulent flow region. $\Delta \mathrm{P} / \mathrm{L}$ was calculated assuming a fully developed steady state Hagen-Poiseuille flow in the loop pipe and using Equation (6) [48]:

$$
\frac{\Delta P}{L}=\frac{f}{D} \frac{1}{2} \rho V^{2} \text { (Darcy formula), }
$$

where $f$ is the friction factor; $D$ is the tube inner diameter (ID); $\rho$ is the fluid density; and $V$ is the average fluid velocity in the pipe. Equations (7) and (8) [49] estimate $f$ for laminar and turbulent flows, respectively:

$$
\begin{gathered}
f=\frac{64}{R e} \text { (Laminar flow), } \\
f=\frac{0.25}{\left[\log _{10}\left(\frac{k_{s}}{3.7 D}+\frac{5.74}{R e^{0.9}}\right)\right]^{2}} \text { (Turbulent flow) (Swamee-Jain equation), }
\end{gathered}
$$

where $k_{s}$ is the surface roughness of the stainless steel pipe which was provided by the manufacturer (AP Miniplant Germany). Equation (9) defines Re as follows:

$$
R e=\frac{\rho V D}{\mu},
$$

where $\mu$ is the dynamic viscosity of the experimental liquid. The thermocouple, placed at the tube discharge and connected to the data acquisition system, measured the corresponding temperature. The dynamic viscosity at this temperature was used to calculate $R e$.

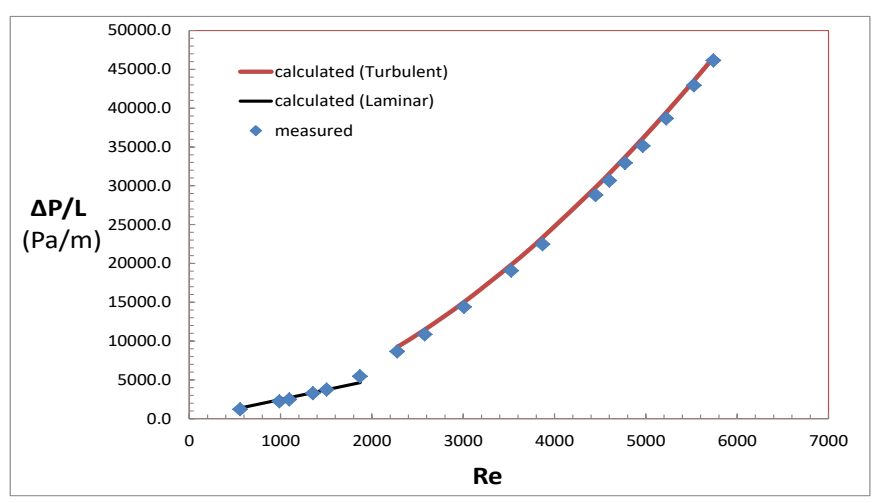

Figure 8. Variation of $\Delta \mathrm{P} / \mathrm{Ls}$ (pressure gradients) with Reynolds number (Re) for a selected grade of kerosene flowing in a 0.4 inch ID horizontal pipe in the loop.

Figure 9 shows the calibration curves without and with a polyisobutene (PIB) DRP. In both figures, the experimental (measured) and calculated $\Delta \mathrm{P} /$ Ls (estimated using Equations (6)-(9)) matched very well. 


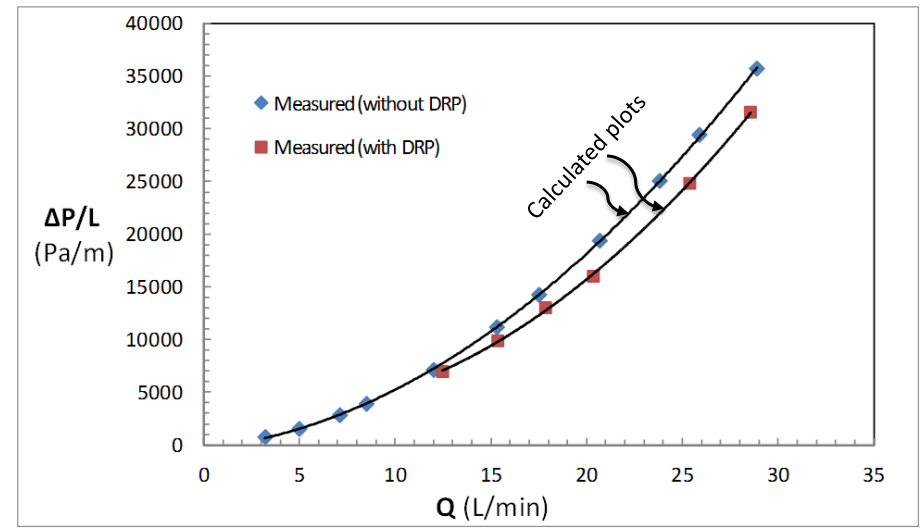

Figure 9. Variation of $\Delta \mathrm{P} / \mathrm{L}$ as a function of volumetric flow rate $\mathrm{Q}$ for UHMW polyisobutene (PIB; a commercial DRP) for $50 \mathrm{ppm}$ concentration in the pipe line.

The dosage pump was calibrated from the lowest to the maximum range before the experiment. The DRP performance was evaluated at $10 \mathrm{~L} / \mathrm{min}$, which gives an average velocity of about $2.1 \mathrm{~m} / \mathrm{s}$ $(6.8 \mathrm{ft} / \mathrm{s})$ in the pipe and $R e=18,850$. This corresponds to highly turbulent flow, typical of a fluid transportation pipe. The DRP flow rate was gradually increased by applying the dosage pump. The concentration of the experimental DRP in the pipeline was calculated using the following:

- Dosage pump flow rate;

- Flow rate of the experimental transportation fluid in the pipe line; and

- The concentration of the DRP master solution.

The \%DR was determined using the following pressure drop relation [50-52]:

$$
\% \text { Drag reduction }=\frac{\Delta P_{P F}-\Delta P_{R D F}}{\Delta P_{P F}} \times 100,
$$

where $\Delta P_{R D F}$ and $\Delta P_{P F}$ are the pressure drops (corresponding to the same flow rate) over a given length of pipe for the experimental fluid with and without the DRP, respectively.

\section{Future Challenges and Research Niches}

This section addresses future challenges and research niches in DRP catalyst and process development, surfactant-based product formulation development, and turbulent mixing and dispersion models in transportation pipeline and DRP injection. These are categorically summarized below.

\subsection{DRP Catalyst and Process Development}

The developments of high-performance DRP catalysts and processes are inter-related. The current process and catalyst mostly synthesize a single-phase solution product. They require a very low temperature and lengthy polymerization time. Undesirable rod-climbing effect occurs with progression of polymerization due to stirring as viscosity develops and normal stress exceeds tangential stress. This adversely affects macro- and micromixing of the highly viscous reaction mixture. Consequently, consistency in product quality deteriorates. The resulting product dissolves in the alpha-olefin comonomers and the solvent used. This prevents achieving in-situ particulate morphology (during polymerization), which is a major catalyst-cum-process development challenge. Such an as-synthesized DRP morphology can make significantly improved product formulation.

Comprehensive investigation of precatalyst-cocatalyst-donor complexation and dissociation behavior, precatalyst-cocatalyst molecular separation, and product microstructural characterization can further elucidate the catalyst and DRP process performance. These subjects have been either unfortunately undone or unpublished. 


\subsection{Surfactant-Based DRP Formulation Development}

The UHMW DRP, dissolved in a suitable solvent, is a highly viscous product. The product development challenges list the following:

- Viscofication-free pumpable and stable slurry;

- Tendency to aggregate, gel, and layer with the passage of time;

- Phase separation instability;

- Transportation inconvenience;

- Inadequate DRP dissolution within the turbulent mixing length; and

- Difficulty in achieving very high extensional viscosity.

The currently used cryogenic and grinding process-a prerequisite to DRP formulation-is very cumbersome and costly. This requires maintaining the storage and transportation temperature above certain critical value. Heated injectors are also to be often used to introduce the DRP into the transportation line. Dipropylene glycol monomethyl ether (DPGME) is widely used. This oxidizes readily in air to form unstable peroxides that may explode spontaneously. Most seriously, cryogenic grinding destructs the UHMW polymer backbones. Consequently, the DRP performance significantly decreases.

To overcome the above problems, the DRP must be transformed into a formulated dispersion/emulsion that should comprise the following components. The DRP, devoid of the $\mathrm{O}-\mathrm{H}$ bond, itself makes the dispersed nonpolar phase. This is, in turn, mixed with a liquid carrier (LC) and dispersion aids. The LC is polar (having an O-H bond), and it does not dissolve the DRP but may swell it. It consists of several mutually miscible constituents such as alcohol, glycol, and glycol ether, all of which contain the $\mathrm{O}-\mathrm{H}$ bond. The glycol and glycol ether may act as co-dispersant, too. The dispersion aids include partitioning agent, wetting agent, dispersant, and nonionic surfactant. Depending on the physical form, chemical structure, and temperature, the dispersion aids may be miscible to soluble in the polar liquid carrier. Therefore, the overall product formulation, under such a situation, is a nonpolar-polar $(\mathrm{O} / \mathrm{W})$ emulsion/dispersion.

As per the above summary, the interaction among a selected nonpolar DRP, polar liquid carrier, and dispersion aids must be evaluated as a function of composition and temperature. The interaction between a liquid carrier and a dispersion aid can be a sub-set of this study. In particular, the following should be determined or modeled [53]:

- Surfactant properties;

- DRP swelling;

- Surface interaction;

- Self-assembly of surfactants;

- Surfactant micelle scission free energy;

- Interaction and repulsive parameters; and

- Surfactant critical micelle concentration.

Using modern molecular simulation approach, such as Materials Studio ${ }^{\mathrm{TM}}$, it is possible to quantify the above interactions and greatly facilitate the development of advanced DRP formulations.

\subsection{Turbulent Mixing and Dispersion Models in Transportation Pipeline and DRP Injection}

The DRP pipeline injection problems include the following:

- Inconsistent pumping and feeding;

- Inadequate dispersion and mixing under turbulent fluid flow; and

- Turbulence- and shear-induced mechanical degradation. 
Models that can illustrate particularly inter-phase interaction, dispersion, and mixing of DRP with the fluid of interest under turbulent flow dynamics are fairly inadequate [54,55]. Research in this area can significantly improve DRP injection methodology.

\section{Conclusions and Perspectives}

\subsection{Conclusions}

Crude oil and refinery products are transported worldwide to meet human energy needs. During transportation, the fluid pressure drastically drops in the pipeline due to interfacial friction between the pipe wall and the flowing fluid. Highly expensive ultrahigh molecular weight (UHMW, MW $\geq a$ million Dalton) drag reducing polymers (DRPs) are currently used to address this problem. DRPs are synthesized using linear alpha-olefins and second generation Ziegler-Natta catalysts. A high performance catalyst can develop a cost-effective commercial DRP process. This is why the present study particularly addresses how to enhance DRP catalyst activity.

The novel concept underlying the present catalyst system, which involves precatalyst-cocatalyst molecular separation and cocatalyst monophenyl amine association-dissociation phenomena, has been patented, schematically illustrated, and experimented. The premier contributions of this catalyst system are as follows. Its activity was 1.4 times that of the reference catalyst. The resulting 1-hexene-1-dodecene DRP copolymer almost tripled the rate of transportation of a selected grade of refinery product and saved about $50 \%$ pumping energy at ppm level pipeline concentration. This catalyst also regulated the copolymer microstructure in such a manner that a lower MW value UHMW product could also achieve commensurate DR\%. This finding will set new directions in drag reduction and DRP rheology research. The current catalytic copolymerization shows promise to shift the DRP synthesis process from $0{ }^{\circ} \mathrm{C}$ and below to room temperature and above. Future research challenges and opportunities in overall DRP research have been outlined.

\subsection{Perspectives}

The background and importance of this research well aligned with a key part of Saudi Arabia's Vision 2030-conversion of local raw materials into value-added products. Saudi Aramco at present imports a huge volume of highly expensive DRPs for transporting crude oil and refinery products despite several basic materials being locally available. Almuttahida (Jubail United Petrochemical Company) produces the required alpha-olefins and Saudi Organometallic Chemicals Company (SOCC Al-Jubail) makes the related alkyl aluminum cocatalyst. Hence, several compelling success factors are already available. To develop, therefore, an indigenous DRP technology using Almuttahida alpha-olefins and SOCC cocatalyst is appropriate. We envisioned to build a world-class DRP research program at KFUPM (to be led by the Center for Refining and Petrochemicals). This will eventually serve a great national cause. We anticipated Saudi Aramco would continue to play a critical collaborative role in this regard. It may be noted that KFUPM and Saudi Aramco (currently holding 70\% of SABIC share) are neighbors. Both are under the Saudi Ministry of Energy, and DRP research concerns energy conservation.

\section{Patents}

Three US patents resulted from this work [38-40] (collaboration of KFUPM with Saudi Aramco).

Author Contributions: Conceptualization, M.A.; methodology, M.A., A.H.A.-S., F.M.A.-T.; investigation, M.A., A.H.A.-S., F.M.A.-T.; resources, M.A., F.M.A.-T., A.R.A.-M.; writing-original draft preparation, M.A., A.H.A.-S., H.S.A.; writing-review and editing, M.A., A.H.A.-S., A.R.A.-M.; supervision, M.A.; project administration, M.A., F.M.A.-T., A.R.A.-M.; funding acquisition, M.A.

Funding: We highly appreciate Saudi Aramco for supporting this research through PN CRP02253 under University Collaboration Program (UCP). The donation of selected higher alpha-olefins (1-hexene and 1-dodecene) by Almuttahida SABIC is also thankfully acknowledged. 
Acknowledgments: The authors thankfully acknowledge King Fahd University of Petroleum \& Minerals, Dhahran, Saudi Arabia for supporting this study. The assistance of Anwar Hossaen and Jaber Al-Qahtani, Center for Refining \& Petrochemicals is appreciated.

Conflicts of Interest: The authors declare no conflict of interest.

\section{References}

1. Crude Oil Production Statistics | Crude Oil | Enerdata. Available online: https://yearbook.enerdata.net/crudeoil/production-statistics.html.

2. Oil Consumption by Region | Oil Energy Consumption Statistics | Enerdata. Available online: https: //yearbook.enerdata.net/oil-products/world-oil-domestic-consumption-statistics.html.

3. Mowla, D.; Naderi, A. Experimental study of drag reduction by a polymeric additive in slug two-phase flow of crude oil and air in horizontal pipes. Chem. Eng. Sci. 2006, 61, 1549-1554. [CrossRef]

4. Hasan, S.W.; Ghannam, M.T.; Esmail, N. Heavy crude oil viscosity reduction and rheology for pipeline transportation. Fuel 2010, 89, 1095-1100. [CrossRef]

5. Martínez-Palou, R.; Mosqueira, M.d.L.; Zapata-Rendón, B.; Mar-Juárez, E.; Bernal-Huicochea, C.; de la Cruz Clavel-López, J.; Aburto, J. Transportation of heavy and extra-heavy crude oil by pipeline: A review. J. Pet. Sci. Eng. 2011, 75, 274-282. [CrossRef]

6. Alsurakji, I.; Al-Sarkhi, A.; Atiqullah, M.; Alhems, L.; El Nakla, M. Study of oil-soluble and water-soluble drag reducing polymers in multiphase flows. Can. J. Chem. Eng. 2018, 96, 1012-1028. [CrossRef]

7. Al-Roomi, Y.; George, R.; Elgibaly, A.; Elkamel, A. Use of a novel surfactant for improving the transportability/transportation of heavy/viscous crude oils. J. Pet. Sci. Eng. 2004, 42, 235-243. [CrossRef]

8. Toms, B.A. Some observations on the flow of linear polymer solutions through straight tubes at large Reynolds numbers. In Proceedings of the First International Congress on Rheology, Scheveningen, The Netherlands, 21-24 September 1948; Volume 2, pp. 135-141.

9. Motier, J.F.; Carrier, A.M. Recent studies on polymer drag reduction in commercial pipelines. In Drag Reduction in Fluid Flows: Techniques for Friction Control; Sellin, R., Moses, R., Eds.; Ellis Horwood: West Sussex, UK, 1989; pp. 197-204.

10. Nijs, L. New generation drag reducer. In 2nd Pipeline Technology; Ostend, B., Denys, R., Eds.; Elsevier: Amsterdam, The Netherlands, 1995; pp. 143-149.

11. Dujmovich, T.; Gallegos, A. Drag reducers improve throughput, cut costs. Offshore 2005, 65, 1-4.

12. Motier, J.F.; Chou, L.C.; Kommareddi, N.S. Commercial drag reduction past, present and future. In Proceedings of the ASME Fluids Engineering Division Summer Meeting; ASME: San Diego, CA, USA, 1996; pp. 229-234.

13. Burger, E.D.; Munk, W.R.; Wahl, H.A. Flow increase in the trans alaska pipeline through use of a polymeric drag-reducing additive. J. Pet. Technol. 1982, 34, 377-386. [CrossRef]

14. Wang, Y. Reynolds stress model for viscoelastic drag-reducing flow induced by polymer solution. Polymers 2019, 11, 1659. [CrossRef]

15. Wang, Y.; Yu, B.; Zakin, J.L.; Shi, H. Review on Drag Reduction and Its Heat Transfer by Additives. Adv. Mech. Eng. 2011, 478749. [CrossRef]

16. Research Institute. Development of Novel Poly(Alpha-Olefin) Drag Reducing Agents for Saudi Aramco Oil and Refinery Products; Final Report CRP02253; King Fahd University of Petroleum \& Minerals: Dhahran, Saudi Arabia, 2015.

17. Alsurakji, I.H.; Al-Sarkhi, A.; Habib, M.; Badr, H.M. An experimental study on the performance of drag reducing polymers in single- and multiphase horizontal flow using particle image velocimetry. J. Energy Resour. Technol. 2018, 140, 052005. [CrossRef]

18. Jing, X.; Liu, Y.; Li, W.; Xu, Y.; Huang, Z. Using water-miscible nonionic hydrophobic monomer associating HPAM as drag reducing agent. J. Appl. Polym. Sci. 2019, 136, 48362. [CrossRef]

19. Jubran, B.A.; Zurigat, Y.H.; Goosen, M.F.A. Drag reducing agents in multiphase flow pipelines: Recent trends and future needs. Pet. Sci. Technol. 2005, 23, 1403-1424. [CrossRef]

20. Manfield, P.D.; Lawrence, C.J.; Hewitt, G.F. Drag reduction with additives in multiphase flow: A literature survey. Multiph. Sci. Technol. 1999, 11, 197-221. [CrossRef]

21. Al-Sarkhi, A. Drag reduction with polymers in gas-liquid/liquid-liquid flows in pipes: A literature review. $J$. Nat. Gas Sci. Eng. 2010, 2, 41-48. [CrossRef] 
22. Al-Yaari, M.; Soleimani, A.; Abu-Sharkh, B.; Al-Mubaiyedh, U.; Al-Sarkhi, A. Effect of drag reducing polymers on oil-water flow in a horizontal pipe. Int. J. Multiph. Flow 2009, 35, 516-524. [CrossRef]

23. Warholic, M.D.; Massah, H.; Hanratty, T.J. Influence of drag reducing polymers on turbulence: Effects of Reynolds number, concentration, and mixing. Exp. Fluids 1999, 27, 461-472. [CrossRef]

24. Dehm, D. Low Temperature Polymerization Process. U.S. Patent 4,384,089, 17 May 1983.

25. Motier, J. Compositions for and Method of Reducing Hydrocarbon Fluid Friction Loss in Conduits. U.S. Patent 4,527,581, 9 July 1985.

26. Smith, G.H.; Perry, D.C. Novel preparation of pure $\beta-\mathrm{TiCl}_{3}$ and its use in isoprene polymerization. J. Polym. Sci. Part A 1 Polym. Chem. 1969, 7, 707-713. [CrossRef]

27. Sementa, L.; D’Amore, M.; Barone, V.; Busico, V.; Causa', M. A quantum mechanical study of $\mathrm{TiCl}_{3}$ alpha, beta and gamma crystal phases: Geometry, electronic structure and magnetism. Phys. Chem. Chem. Phys. 2009, 11, 11264-11275. [CrossRef]

28. Mack, P.; Decker, L.; Wallac, A. Method for the Preparation of Non-Crystalline Polymers of High Molecular Weight. U.S. Patent 4,358,572, 9 November 1982.

29. Mack, P. Polymerization Process for Drag Reducing Substances. U.S. Patent 4493903 A, 15 January 1985.

30. Mack, P. Catalyst and Method for Preparation of Drag Reducing Substances. U.S. Patent 4493904 A, 15 January 1985.

31. Marullo, G.; Baroni, A.; Maffezzoni, U. Three Component Catalyst for Polymerization of 1-Olefins Containing Titanium Halide, Aluminum Alkyl, and Pyridine. U.S. Patent 3,139,418, 30 June 1964.

32. Mack, P. Polymerization Process for Drag Reducing Substances. U.S. Patent 4,433,123, 21 February 1984.

33. Eaton, G.; Monahan, M.; Tipton, R. Methods for Forming Amorphous Ultra-High Molecular Weight Polyalphaolefin Drag Reducing Agents. U.S. Patent 6,015,779, 18 Janurary 2000.

34. Eaton, G.; Monahan, M.; Tipton, R. Methods for Forming Amorphous Ultra-High Molecular Weight Polyalphaolefin Drag Reducing Agents Using a Halocarbon. U.S. Patent 6,162,773, 23 August 2000.

35. Eaton, G.; Monahan, M.; Tipton, R. Methods for forming Amorphous Ultra-High Molecular Weight Polyalphaolefin Drag Reducing Agents Using Non-Metallocene and Alkylaluminoxane. U.S. Patent 6,242,395, 5 June 2001.

36. Eaton, G.; Monahan, M.; Ebert, A.; Tipton, R.; Baralt, E. Methods for Forming Amorphous Ultra-High Molecular Weight Polyolefins for Use as Drag Reducing Agents. U.S. Patent 6,730,750 B2, 4 May 2004.

37. Eaton, G.; Monahan, M.; Tipton, R. Methods for Forming Amorphous Ultra-High Molecular Weight Polyolefins and Drag Reducing Compositions Comprising Amorphous Ultra-High Molecular Weight Polyolefins. U.S. Patent 6,730,752, 4 May 2004.

38. Atiqullah, M.; Al-Sarkhi, A.; Al-Thenayan, F.; Al-Malki, A.; Xu, W.; Hossaen, A. Catalyst Composition for Making Ultrahigh Molecular Weight Poly(Alphaolefin) Drag Reducing Agents. U.S. Patent 10,301,410 B2, 28 May 2019.

39. Atiqullah, M.; Al-Sarkhi, A.; Al-Thenayan, F.; Al-Malki, A.; Xu, W.; Hossaen, A.A. Catalyst Composition and a Process for Making Ultrahigh Molecular Weight Poly(Alphaolefin) Drag Reducing Agents. U.S. Patent 9,969,826 B2, 15 May 2018.

40. Atiqullah, M.; Al-Sarkhi, A.; Al-Thenayan, F.; Al-Malki, A.; Xu, W.; Hossaen, A. Method of Reducing Drag in a Conduit. U.S. Patent 10,287,374 B2, 14 May 2019.

41. Bochmann, M. The chemistry of catalyst activation: The case of group 4 polymerization catalysts. Organometallics 2010, 29, 4711-4740. [CrossRef]

42. Atiqullah, M.; Anantawaraskul, S.; Emwas, A.-H.M.; Al-Harthi, M.A.; Hussain, I.; Ul-Hamid, A.; Hossaen, A. Silica-supported ( $\left.{ }^{\mathrm{B}} \mathrm{BuCp}\right){ }_{2} \mathrm{ZrCl}_{2}$ : Effect of catalyst active center distribution on ethylene-1-hexene copolymerization. Polym. Int. 2014, 63, 955-972. [CrossRef]

43. Ray Smith, B.E. Polymers: A Property Database, 2nd ed.; CRC Press, Taylor \& Francis Group: New York, NY, USA, 2009; ISBN 978-0-8493-3940-0.

44. Atiqullah, M.; Adamu, S.; Emwas, A.H.M. UHMW Ziegler-Natta polyethylene: Synthesis, crystallization, and melt behavior. J. Taiwan Inst. Chem. Eng. 2017, 76, 141-155. [CrossRef]

45. Reding, F.P. Transitions in aliphatic olefin polymers. J. Polym. Sci. 1956, 21, 547-549. [CrossRef]

46. Gordon, M.; Taylor, J.S. Ideal copolymers and the second-order transitions of synthetic rubbers. I. Non-crystalline copolymers. J. Appl. Chem. 2007, 2, 493-500. [CrossRef] 
47. Rodriguez, F.; Cohen, C.; Ober, C.K.; Archer, L.A. Principles of Polymer Systems, 6th ed.; Taylor \& Francis Group: New York, NY, USA, 2014; ISBN 9781482223781.

48. Elger, D.F.; LeBret, B.A.; Crowe, C.T.; Clayton, T.; Roberson, J.A. Engineering Fluid Mechanics, 11th ed.; Wiley: Hoboken, NJ, USA, 2016; ISBN 9781118880685.

49. Swamee, P.; Jain, A. Explicit eqations for pipe-flow problems. ASCE J. Hydraul. Div. 1976, 102, $657-664$.

50. Subhash, N.S.; Ahmed, K.; Yunxu, Z. Drag reduction characteristics in straight and coiled tubing-An experimental study. J. Pet. Sci. Eng. 2006, 53, 179-188.

51. Al-Wahaibi, T.; Smith, M.; Angeli, P. Effect of drag reducing polymers on horizontal oil-water flows. J. Pet. Sci. Eng. 2007, 57, 334-346. [CrossRef]

52. Li, B.; Dong, G.; Zhang, C. Storage stability and solubility of poly(urea-formaldehyde) microcapsules containing $\alpha$-olefin drag reducing polymer. J. Appl. Polym. Sci. 2011, 122, 1450-1456. [CrossRef]

53. Wang, H.; Tang, X.; Eike, D.M.; Larson, R.G.; Koenig, P.H. Scission free energies for wormlike surfactant micelles: Development of a simulation protocol, application, and validation for personal care formulations. Langmuir 2018, 34, 1564-1573. [CrossRef]

54. Hara, S.; Ii, R.; Tsukahara, T.; Kawaguchi, Y. Analysis of an organized turbulent structure using a pattern recognition technique in a drag-reducing surfactant solution flow. Int. J. Heat Fluid Flow 2017, 63, 56-66. [CrossRef]

55. Al-Sarkhi, A. Effect of mixing on frictional loss reduction by drag reducing polymer in annular horizontal two-phase flows. Int. J. Multiph. Flow 2012, 39, 186-192. [CrossRef]

(C) 2019 by the authors. Licensee MDPI, Basel, Switzerland. This article is an open access article distributed under the terms and conditions of the Creative Commons Attribution (CC BY) license (http://creativecommons.org/licenses/by/4.0/). 